\title{
A Proposed Managerial Model for Improvement of Blood Consumption in the Operating Rooms in Southern Iran
}

\author{
Maryam Gholami (iD) ${ }^{1}$, Kamran Hajinabi (iD) ${ }^{1,}$, Leila Riahi ${ }^{1}$ and Sezaneh Haghpanah ${ }^{2}$ \\ ${ }^{1}$ Department of Health Services Management, Science and Research Branch, Islamic Azad University, Tehran, Iran \\ ${ }^{2}$ Hematology Research Center, Shiraz University of Medical Sciences, Shiraz, Iran \\ "Corresponding author: Department of Health Services Management, Science and Research Branch, Islamic Azad University, Tehran, Iran. Email: hajinabi@srbiau.ac.ir
}

Received 2021 July 06; Revised 2021 September 13; Accepted 2021 September 30.

\begin{abstract}
Background: The financial burden of blood wastage in operating rooms of hospitals indicates the importance of managing blood consumption.

Objectives: To determine the most influential factors affecting blood utilization management in operating rooms.

Methods: This cross-sectional study was conducted in the operating rooms of the largest tertiary referral hospital in Southern Iran from September to November 2019. A researcher-made questionnaire was designed, validated, and completed by 185 related stakeholders. Confirmatory factor analysis was conducted.

Results: Model fit indices had acceptable values $(\mathrm{P}=0.032)$. In the suggested model, resource allocation (coefficient $=0.81)$ and control (coefficient $=0.77$ ) were determined as the two most impressive managerial dimensions of blood utilization management. In the resource allocation dimension, the most effective factors were found to be using trained and oriented personnel to inventory management principles and blood bag handling, storage, and transportation rules and providing in-hospital safe and standard blood transportation equipment. In the control dimension, the most influencing subject was evaluating and reporting the reasons for the date expiry of blood products.

Conclusions: Implementing a stepwise evidence-based blood consumption program based on the most prioritized suggested initiatives can be highly cost-effective and presented as a practical guide for policymakers, especially in low socio-economic countries. Based on our results, focusing on using trained blood bank staff in all related parts and providing standard blood transportation equipment as well as attempting to minimize the number of discarded blood units in operating rooms can be highly effective in the reduction of blood wastage and improvement of blood consumption status.
\end{abstract}

Keywords: Blood Usage, Blood Utilization, Blood Wastage, Transfusion

\section{Background}

Blood transfusion is one of the most important health issues in the modern world. Despite extensive advances in various fields of medicine, scientists have not yet been able to find a viable alternative to human blood, so the only source of blood is the already donated blood (1). World Health Organization states that about $87.5 \%$ of developing countries supply less than half of the blood requirements for their populations (2). On the other hand, the demand for blood bags in hospitals depends on the number of daily admission of patients with accident-related injuries, which cannot be well forecasted; therefore, in most cases, forecasting the daily demand of hospitals might not exactly correspond to their real demand (3). Various studies mentioned excessive blood ordering as a major cause of blood wastage (4-6). The importance of demand fore- casting in the blood supply chain process and the criteria for measuring blood utilization in health care settings have been investigated in many studies $(7,8)$. Different management models and targeted interventions, such as using trained personnel for blood product transportation (8) and managing as well as reducing excessive orders of blood $(9,10)$, have been proposed and established in different countries. In Iran, based on comprehensive research during 2005 - 2015, the two main causes of blood product wastage were stated as date expiry and returned/reserved units of operating rooms and wards (1). On the other hand, $34.7 \%$ and $93 \%$ of the red blood cells (RBCs) wastage have been reported in surgery units in different medical centers of Iran $(11,12)$. Lack of standard guidelines for proper blood ordering and consumption is stated as a major problem leading to blood wastage in Southern Iran, as well (13). Enormous costs of preparing blood products, as well as rel- 
ative costs of wasting blood, have received considerable attention from researchers worldwide $(14,15)$. Taken together, implementing efficient interventions for promoting blood product consumption is considered as one of the major health issues, especially in developing countries that are facing limitations in blood supply.

\section{Objectives}

Therefore, this study was designed to suggest an effective blood consumption management model based on determining the most influential initiatives using stakeholders' opinions in the operating rooms of the largest tertiary referral hospital in Southern Iran.

\section{Methods}

In this cross-sectional study, 185 participants, consisting of 10 anesthesiologists, 33 surgeons, 75 anesthesiology technicians, and 67 surgical technicians, were enrolled during September and November 2019 in the Nemazee Hospital, the largest tertiary referral center in Southern Iran. Inclusion criteria were all anesthesiologists, surgeons, anesthesiology technicians, and surgical technicians working in the operating rooms during the study period who were willing to cooperate with us. Based on Mundfrom et al.'s study (16), the suggested minimums for the sample size are 3 to 20 times the number of variables. Therefore, our sample size is enough for confirmatory factor analysis (8 samples per item). The study protocol was approved by the Ethical Committee of the Islamic Azad University (ethics code: IR.IAU.SRB.REC.1398.078, approval code $=15899$ ).

In the first step, a comprehensive literature search was done to determine the effective factors and initiatives previously reported for improvement of blood consumption management and decreasing blood wastage (Table 1).

\subsection{Search Strategy}

Quantitative studies, including descriptive, observational, interventional, meta-analysis, and systematic review, as well as qualitative studies in the field of blood bag consumption management, were reviewed. Factors affecting the management of blood bag consumption were effectively examined to identify and investigate the patterns of blood bag consumption management. Databases and electronic articles, international and national, were searched through academic and non-academic digital networks. Restrictions on access to some of the databases made the search period longer and more limited. We searched international databases of PubMed, ProQuest,
Ovid, Scopus, Web of Science, and CINAHL, as well as national databases (SID, Magiran, Iran doc, and Iranmedex) using various combinations of keywords related to the subject of "a proposed managerial model for improvement of blood consumption in the operating rooms in Southern Iran", was searched. The criterion in this section was the availability of information and programs, and the keywords of "hospital management", "blood bags", "blood consumption”, "blood management", "blood wastage” and "operating room" were used.

Data on the following items were collected: year of study, country of study, study method, study tools, and study results. Afterward, the indicators related to blood bag consumption management in developed and developing countries and factors affecting blood bag consumption management based on the five management dimensions were collected, and a preliminary model was formed.

In the second step, an expert panel was formed to develop an appropriate localized questionnaire. The invited experts were stakeholders of the transfusion practice in the hospital, including anesthesiologists, surgeons, and blood bank experts. Using the searched items and new suggestions, which were obtained using the brainstorming methods in 10 sessions, a total of 19 factors were identified as the potential influencing factors on the blood consumption management in our situation and presented as a researcher-made questionnaire with 23 items scored on a Likert scale. The effectiveness of each item on blood consumption management was considered as very low, low, moderate, high, and very high, which were ranked based on the viewpoints of the participants.

In the third step, the validity and reliability of the questionnaire were evaluated. To confirm the content validity ratio (CVR) and content validity index (CVI) (29), the questionnaire was evaluated by 10 experts in the fields of surgery, anesthesiology, epidemiology, $\mathrm{PhD}$ in the blood bank, and Ph.D. in hospital management to express their views on the quality of the items and help us to construct an appropriate questionnaire (29). Based on the Lawshe table, the minimum acceptable CVR (according to the number of evaluators) $(29,30)$, and the acceptable amount of CVI, all suggested factors obtained the required score to be included in the questionnaire (the acceptable value was 0.62 for CVR and 0.79 for CVI). Also, the reliability of the questionnaire was determined by internal consistency, with a Cronbach's alpha of $88.9 \%$ obtained from a randomly selected sample $(n=50)$ from our studied population.

In the final step, the questionnaire was distributed to the participants to determine their opinions regarding the degree of effectiveness and prioritize areas of focus on blood consumption management. For better evaluation, 


\begin{tabular}{|c|c|c|c|c|c|}
\hline Author & Year & Country & Type of study & Problems/Aims & Factors/Interventions \\
\hline Heitmiller et al. ( 8 ) & 2016 & USA & Interventional & $\begin{array}{l}\text { Product obsolescence due to } \\
\text { inaccurate detection of temperature } \\
\text { index along the route }\end{array}$ & $\begin{array}{l}\text { Increase access to blood transfusion tanks, use of } \\
\text { objective tools such as labels and posters on tanks, } \\
\text { and train transport officials }\end{array}$ \\
\hline Venugopal et al. (17) & 2017 & India & Interventional & $\begin{array}{l}\text { Evaluate the use of process } \\
\text { improvement tools }\end{array}$ & $\begin{array}{l}\text { The uniqueness of the staff and operator of the donor } \\
\text { reception and guidance department to fill out the } \\
\text { pre-donation form. Only one donor enters the } \\
\text { pre-test room and medical examination room at a } \\
\text { time to protect donor privacy and designating a } \\
\text { separate waiting area for donors }\end{array}$ \\
\hline Jovanovic et al. (18) & 2013 & Serbia & Interventional & $\begin{array}{l}\text { Optimal use of blood products and } \\
\text { minimizing the cost of blood loss }\end{array}$ & $\begin{array}{l}\text { Implementation of the new Progress information } \\
\text { system at the Blood Transfusion Institute }\end{array}$ \\
\hline Improta et al. (19) & 2015 & Italy & Interventional & $\begin{array}{l}\text { Reduce blood loss in the hospital and } \\
\text { health care center }\end{array}$ & $\begin{array}{l}\text { Multiple interventions and corrective actions to } \\
\text { improve the efficiency of the care process }\end{array}$ \\
\hline Toledo et al. (20) & 2013 & Colombia & Interventional & Enforcement of FIFO law & $\begin{array}{l}\text { Clear expectations, improved teamwork, and a } \\
\text { multidisciplinary clinical course }\end{array}$ \\
\hline Soleymani et al. (21) & 2016 & Iran & Interventional & $\begin{array}{l}\text { Non-consumption and return of } \\
\text { blood packages from the wards or } \\
\text { negligence of blood bank personnel } \\
\text { to check the date of consumption of } \\
\text { blood packages }\end{array}$ & $\begin{array}{l}\text { Use of elusive blood care system based on tracer } \\
\text { system }\end{array}$ \\
\hline $\begin{array}{l}\text { Alavi-Moghaddam et } \\
\text { al. (22) }\end{array}$ & 2014 & Iran & Interventional & $\begin{array}{l}\text { Ordering and consumption more } \\
\text { than the need for blood }\end{array}$ & Type and screen protocol \\
\hline Najafi et al. (23) & 2017 & Iran & $\begin{array}{l}\text { Observational } \\
\text { analytical }\end{array}$ & $\begin{array}{l}\text { Excessive blood supply and } \\
\text { unnecessary transfusions }\end{array}$ & $\begin{array}{l}\text { Considering the "demand and supply uncertainty" } \\
\text { factor that exists in the real world. Considering } \\
\text { factors such as the certainty of the blood bank's } \\
\text { knowledge of the actual age of the blood received, } \\
\text { Using Cross Matching electronic system based on } \\
\text { blood bank information system to ensure the } \\
\text { compatibility of donor and patient blood, } \\
\text { Cross-match blood reservation for more than one } \\
\text { patient, Determining the quality of blood as the age } \\
\text { of the transferred blood. }\end{array}$ \\
\hline Brue (24) & 2015 & USA & Interventional & $\begin{array}{l}\text { Improper blood storage and } \\
\text { transportation }\end{array}$ & $\begin{array}{l}\text { Training programs, print, and digital messages, and } \\
\text { ways to improve transportation and identify } \\
\text { components }\end{array}$ \\
\hline Whitney et al. (25) & 2015 & USA & Interventional & Enforcement of FIFO law & $\begin{array}{l}\text { 1) Delivery of RBCs through pneumatic tube system, } \\
\text { 2) No storage of RBCs in operating room refrigerators, } \\
\text { 3) Lack of feedback on events leading to the loss of } \\
\text { RBCs in surgeries, 4) Training of anesthesia and } \\
\text { nursing staff in the area of liver transplantation }\end{array}$ \\
\hline Kanani et al. (26) & 2017 & India & Interventional & $\begin{array}{l}\text { Unnecessary orders, improper } \\
\text { storage, and transportation of blood }\end{array}$ & $\begin{array}{l}\text { 1) Use of advanced software in blood banks and } \\
\text { general rooms of hospitalized patients, 2) Continuous } \\
\text { medical training to technical personnel to empower } \\
\text { them,3) Understanding the quality indicators of } \\
\text { processing and preparation of blood components } \\
\text { and monitoring the rational use of blood }\end{array}$ \\
\hline $\begin{array}{l}\text { Javadzadeh } \\
\text { Shahshahani et al. } \\
\text { (27) }\end{array}$ & 2016 & Iran & Interventional & $\begin{array}{l}\text { Expiry date due to non-return of } \\
\text { blood to the blood bank, } \\
\text { non-compliance with standards in the } \\
\text { blood preparation process }\end{array}$ & $\begin{array}{l}\text { Reducing RBCs to } 7 \text { days in the hospital, managing } \\
\text { blood loss using standard operating procedures, } \\
\text { regular staff training programs including standard } \\
\text { methods of blood collection, processing, } \\
\text { transportation and storage based on standard } \\
\text { operating procedures Iranian Blood Transfusion } \\
\text { Organization (IBTO), distribution and transfer of } \\
\text { blood units between hospitals and regulatory centers } \\
\text { for blood loss }\end{array}$ \\
\hline Anani et al. (28) & 2018 & Iran & Interventional & $\begin{array}{l}\text { Implement payment tariffs for blood } \\
\text { products }\end{array}$ & Implement payment tariffs for blood products \\
\hline
\end{tabular}


related items of the questionnaire were classified into $5 \mathrm{di}$ mensions of planning, organization process, resource allocation, leadership, and control.

\subsection{Statistical Analysis}

Data analysis was administered using AMOS version 21. A general model for the improvement of blood bag management was designed and evaluated by confirmatory factor analysis (CFA). In the confirmatory factor analysis, the researcher designs and tests the path model and the relationships between the obvious and the latent variables obtained based on previous information (14). Then, we described the fit index of the model, including Root Mean Square Error of Approximation (RMSEA < 0.05), Comparative Fit index (CFI > 0.90), Tucker-Lewis index (TLI > 0.90), and $\chi^{2} / \mathrm{df}(<2)$. Statistical significance was considered when P-value $<0.05$.

\section{Results}

Data of 185 participants (60 (32.5\%) females and 125 (67.5\%) males), with a mean age of $40.63 \pm 12.31$ years were analyzed. The CFA model is depicted in Figure 1. Five dimensions influencing blood consumption management in descending order were as follows: Resource allocation, control, and leadership, planning, and organization process.

Factor loading values of each factor are shown in Table 2 . The standardized coefficients and a significant number of items are demonstrated in Table 3. Model fit indices had acceptable values, indicating the appropriateness of the proposed model $(\mathrm{P}=0.032)$ (Table 4 ).

Table 5 demonstrates the most impressive interventions for improving blood consumption management in operating rooms based on the calculated coefficients in the suggested model. Interventions with less impact on blood consumption management in each dimension were as follow:

Resource Allocation: Q5: Considering full-time specific blood bank experts in the operating rooms for supervising blood consumption process (0.69).

Control: Q19: Monitoring and tracing electronic data of blood bag consumption (0.61); Q1: Annual supervision of blood products use by blood supply institutions and hospitals (0.57).

Leadership: Q8: Preparing and implementing problem-based guidelines for blood consumption in each ward such as Maximum Surgical Blood Ordering Schedule (MSBOS) (0.51);

Q9 1-3: Developing an educational program on blood consumption management via electronic program (0.46), sessions, lectures, and workshops (0.49), or pamphlets and books (0.47);

Q10: The possibility of transportation of the unused blood bags between hospitals in one city (0.54);

Q14 1-2: Correcting anemia before operation in outpatient clinics and hospitals (0.49) or specific stations of blood transfusion organization in each city (0.42).

Planning: Q18: Convincing the hospital management to establish a coherent electronic system for recording blood data (0.51);

Q2 1-2: Annual reporting of blood utilization indices via the website $(0.49)$ or quarterly blood product bulletin (0.45).

Organization process: Q13: Careful review of electronic medical records of surgical patients before surgery by the responsible physician (0.58),

Q4: Designing an Intranet website to better transfer blood consumption data between hospital wards (0.46).

\section{Discussion}

In the present study, factors and initiatives affecting the management of blood consumption in operating rooms were studied in a large tertiary referral hospital in southern Iran. The most impressive and practical interventions were determined based on the viewpoints of the surgeons, anesthesiologists, and technicians of the operating rooms and proposed as an effective model.

In the suggested model, resource allocation was determined as the most impressive managerial dimension, which its most effective factor was using trained and oriented personnel to inventory management principles and blood bag handling, storage, and transportation rules, followed by providing in-hospital safe and standard blood transportation equipment. Therefore, providing the required efficient and appropriate transportation equipment, such as monitoring temperature devices and specific protective boxes for different types of blood products, as well as suitable allocation of skilled personnel, not only can substantially reduce blood wastage but also improve blood bag consumption management in the hospital. In the same vein, Javadzadeh Shahshahani et al. (31) and Heitmiller et al. (8) showed that the use of trained personnel for transporting blood bags reduced the wastage of blood bags. Also, inappropriate transportation equipment has been recognized as one of the important factors causing $\mathrm{RBC}$ wastage in previously reported articles $(8,9)$. Moreover, Bots et al. (32) showed that straightforward interventions, particularly improving transport conditions, had a clear impact on the level of RBC wastage.

The second most influential dimension was "control". In this facet, the most impressive subject was evaluating 


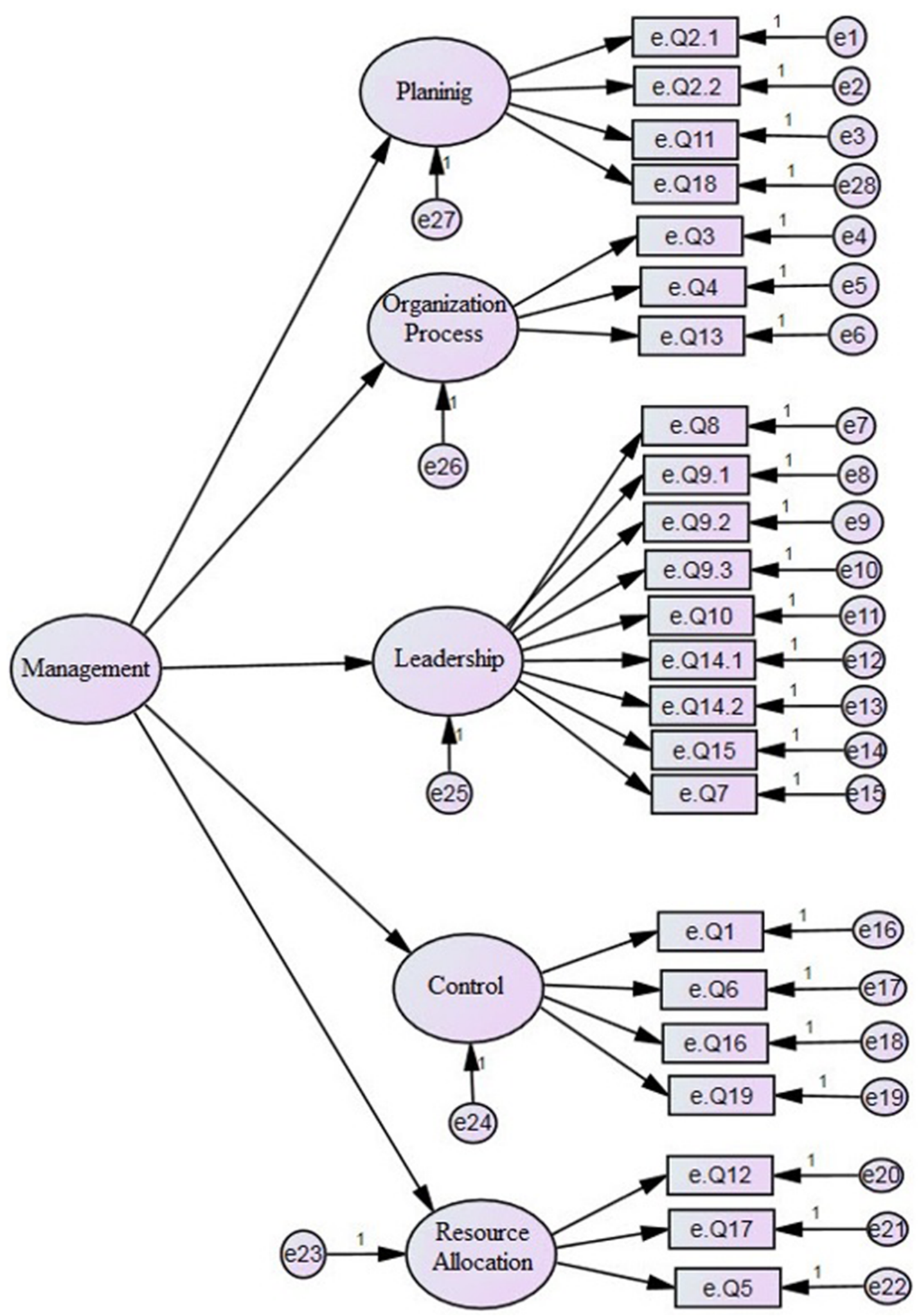




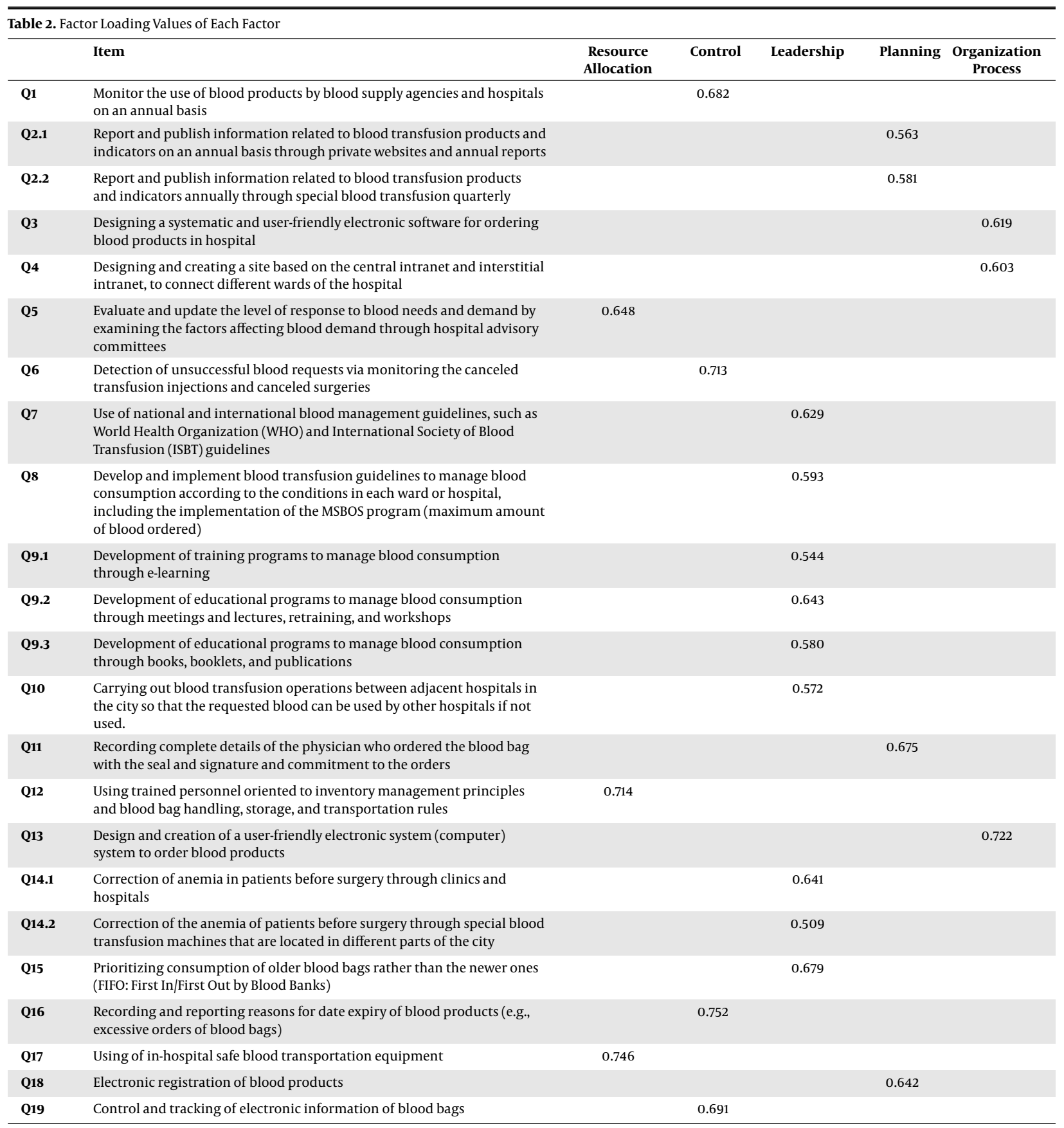

and reporting reasons for the expiry date of blood products, such as excessive orders of blood bags in operating rooms. In accordance with our results, excessive order of blood was suggested as one of the major causes of blood wastage in several studies $(9,27,33)$. Another important problem in our center that leads to a high amount of blood wastage is a high frequency of canceled transfusion injections, mainly due to canceled surgeries. It seems that im- plementing a designed control program can be highly efficient in this regard. Generally, managing the inventory by careful assessment of blood product supply and demand is one of the crucial issues in blood consumption management (34).

Concerning leadership, prioritizing consumption of older blood bags, rather than newer ones (FIFO: first in/first out), by blood banks was the most important factor in- 


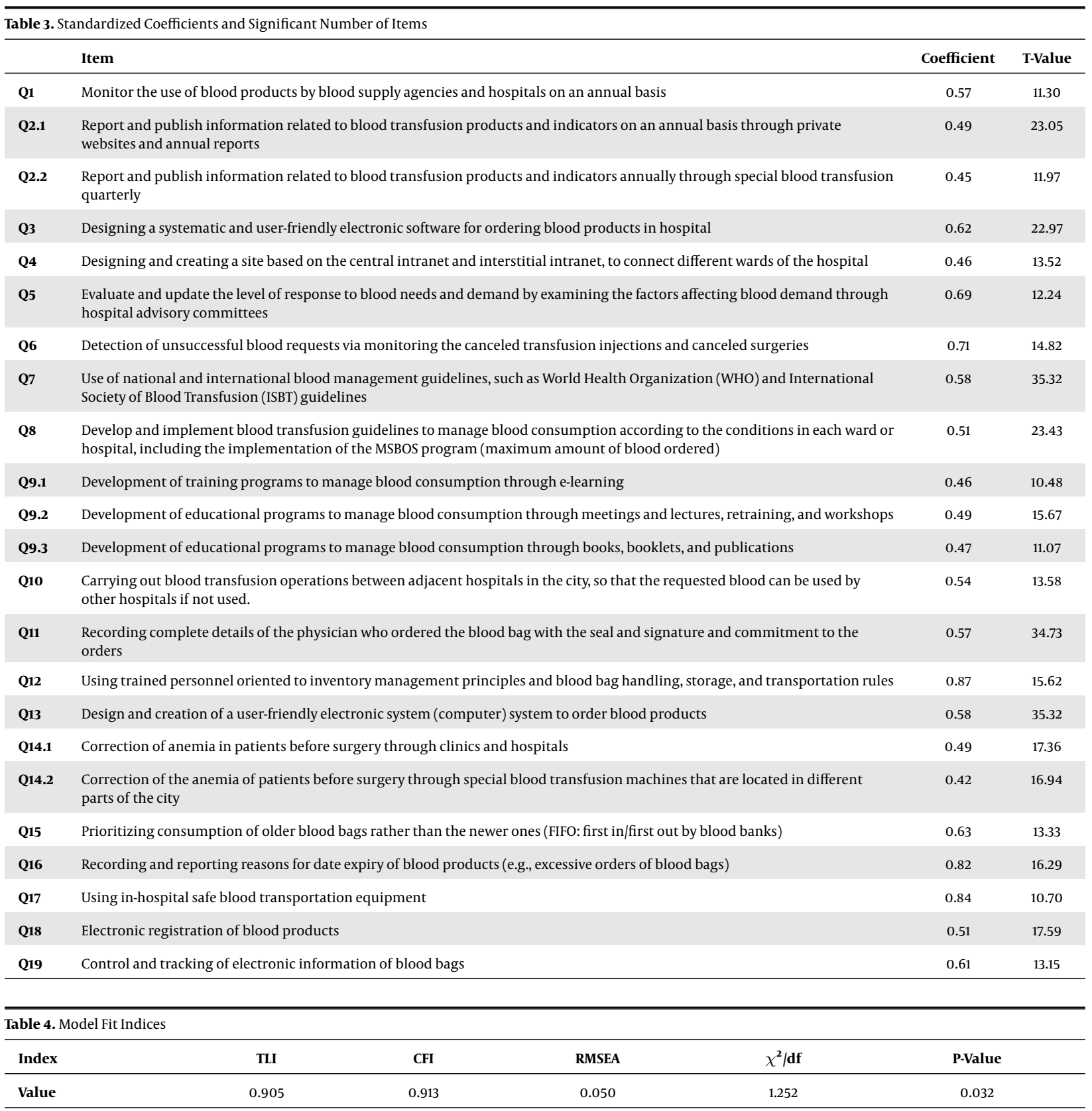

${ }^{\mathrm{z}}$ Abbreviations: CFI, comparative fit index; RMSEA, root mean square error of approximation; TLI, Tucker-Lewis index.

fluencing the management of blood usage in operating rooms. Our finding was similar to those of Stanger et al.'s (35) study, which showed that FIFO was one of the most important disciplines in reducing wastage. Likewise, Soleymani et al. (21) detected a 75\% reduction rate in the loss of blood bags after implementing the FIFO law. The use of national and international blood management guidelines was recognized as another important factor improving blood consumption management, which should be taken into account with more caution.

In the planning dimension, creating responsibility for those ordering blood bags by signing and recording the details seems to be effective in increasing attention towards the appropriate ordering of blood products and decreasing the rate of wastage. In the last dimension, designing a systematic and user-friendly electronic software for registration of all data related to blood products was identified as the most important factor that can decrease blood 


\begin{tabular}{|c|c|c|}
\hline Dimension & Items & Coefficient \\
\hline \multirow{2}{*}{ Resource allocation } & $\begin{array}{l}\text { Q12: Using trained personnel oriented to inventory management principles and blood bag } \\
\text { handling, storage, and transportation rules }\end{array}$ & 0.87 \\
\hline & Q17: Using in-hospital safe blood transportation equipment & 0.84 \\
\hline \multirow{2}{*}{ Control } & $\begin{array}{l}\text { Q16: Recording and reporting reasons for date expiry of blood products (e.g., excessive } \\
\text { orders of blood bags) }\end{array}$ & 0.82 \\
\hline & $\begin{array}{l}\text { Q6: Detecting unsuccessful blood requests via monitoring the canceled transfusion } \\
\text { injections and canceled surgeries }\end{array}$ & 0.71 \\
\hline \multirow{2}{*}{ Leadership } & $\begin{array}{l}\text { Q15: Prioritizing consumption of older blood bags rather than the newer ones (FIFO: First } \\
\text { In/First Out by Blood Banks) }\end{array}$ & 0.63 \\
\hline & $\begin{array}{l}\text { Q7: Using national and international blood management guidelines, such as World Health } \\
\text { Organization (WHO) and International Society of Blood Transfusion (ISBT) guidelines }\end{array}$ & 0.58 \\
\hline Planning & $\begin{array}{l}\text { Q11: Recording complete details of the physician who ordered the blood bag with the seal } \\
\text { and signature and commitment to the orders }\end{array}$ & 0.57 \\
\hline Organization Process & $\begin{array}{l}\text { Q3: Designing a systematic and user-friendly electronic software for ordering blood } \\
\text { products in hospital }\end{array}$ & 0.62 \\
\hline
\end{tabular}

wastage at the hospital. It seems that in developing countries, including Iran, this important issue has been neglected due to the shortage of financial resources; however, establishing a systematic electronic system for data registry translates into improved monitoring and tracking of inventories, resulting in better management and will be highly cost-effective in the field of blood consumption.

From less important influencing factors, implementation of problem-based guidelines for blood consumption in each ward, such as MSBOS, and establishment of a regular educational program with different teaching methods for related staff should be taken into consideration as well.

Our study was limited due to using data from a single center; however, as mentioned above this center was the largest referral tertiary center in Southern Iran.

\subsection{Conclusions}

While blood wastage is inevitable, situation analysis and determination of the most influential initiatives by related stakeholders in this field can effectively aid in the promotion of blood transfusion practice. Improvement in resource allocation was determined as the most influential dimension by focusing on using trained blood bank staff oriented to inventory management, handling, and transportation rules, as well as providing standard blood transportation equipment. Implementing a stepwise evidencebased blood consumption program based on the most prioritized suggested initiatives in the proposed model can be highly cost-effective in this respect.

\section{Footnotes}

Authors' Contribution: Maryam Gholami and Kamran Hajinabi: Designing and planning. Leila Riahi: Designing and final edit. Sezaneh Haghpanah: Designing, final edit, and analyze.

Conflict of Interests: The authors declare no conflicts of interest.

Ethical Approval: The study protocol was approved by the Ethical Committee of the Islamic Azad University (ethics code: IR.IAU.SRB.REC.1398.078, approval code = 15899).

Funding/Support: The author(s) received no financial support for the research, authorship, and/or publication of this article.

\section{References}

1. Amini Kafi-Abad S, Omidkhoda A, Pourfatollah AA. Analysis of hospital blood components wastage in Iran (2005-2015). Transfus Apher Sci. 2019;58(1):34-8. doi: 10.1016/j.transci.2018.11.001. [PubMed: 30477936].

2. Kurup R, Anderson A, Boston C, Burns L, George M, Frank M. A study on blood product usage and wastage at the public hospital, Guyana. BMC Res Notes. 2016;9:307. doi: 10.1186/s13104-016-2112-5. [PubMed: 27297566]. [PubMed Central: PMC4907253].

3. Filho OS, Carvalho MA, Cezarino W, Silva R, Salviano G. Demand Forecasting for Blood Components Distribution of a Blood Supply Chain. IFAC Proceed Vol. 2013;46(24):565-71. doi: 10.3182/20130911-3-br3021.00092.

4. Tolyat M, Barakchi AA. Evaluation of blood utilization in Birjand Imam Reza Hospital. Sci J Iran Blood Transfus Organ. 2014;10(4):400-5.

5. Aqmasheh S, Shamsasenjan K. The evaluation of blood crossmatches and blood utilization at university hospitals in Tabriz. Sci J Iran Blood Transfus Organ. 2016;13(4):259-68.

6. Rezaie M, Khaleghian A, Alizadeh F, Mirmohamadkhani M. The number of the requests for, transfusion and the wastage of blood and blood components basenumber of cross-matched blood to transfusion $(\mathrm{C} / \mathrm{T}) \mathrm{d}$ on the ratio of the in Semnan hospitals in 1394. Sci J Iran Blood Transfus Organ. 2019;16(1):9-16.

7. Zaman B, Radmehr MOHAMMAD, Sahraian A, Sohrabi P. Determination of the ratio and causes of unused blood ordered from blood bank 
blood in elective surgery in Rasoul-e-Akram Hospital. Sci J Iran Blood Transfus Organ. 2009;6(2):141-6.

8. Heitmiller ES, Hill RB, Marshall CE, Parsons BJ, Berkow LC, Barrasso CA, et al. Blood wastage reduction using Lean Sigma methodology. Transfusion. 2010;50(9):1887-96. doi: 10.1111/j.1537-2995.2010.02679.x. [PubMed: 20456700].

9. Zoric L, Daurat G, Demattei C, Macheboeuf M, Boisson C, Bouix O, et al. Blood wastage reduction: a 10-year observational evaluation in a large teaching institution in France. Eur JAnaesthesiol. 2013;30(5):2505. doi: 10.1097/EJA.0b013e32835fadcf. [PubMed: 23535198].

10. Singh JK, Singh P. Routine pre-operative cross-match for elective colorectal resections: an appropriate use of resources? Surgeon. 2011;9(1):8-12. doi:10.1016/j.surge.2010.06.008. [PubMed: 21195324].

11. Lookzadeh MH, Adhami F, Nouri Shadkam M, Mirjalili SR, Sheikhpour E. The Frequency of Packed Red Blood Cells Transfusion in Preterm Infants Admitted to NICU of Shahid Sadoughi Hospital During 2016. Iran J Pediatr Hematol Oncol. 2019. doi:10.18502/ijpho.v9i2.609.

12. Miri-Moghaddam E, Tahmasebi A, Khedria S, Khosravi S. Determination of Blood components Utilization Pattern in Zahedan City, Southeast of Iran. Modern Care Journal. 2020;17(1). doi: 10.5812/modernc.97586.

13. Khazaei A, Jahromi AS, Khoshfetrat M, Behnampoor M, Jahandideh M. Monitoring blood consumption with emphasis on MSBOS table in Educational Hospitals Zahedan, Iran, 2014. J Res Med Dent Sci. 2018;6(2):574-7.

14. Berwick DM, Hackbarth AD. Eliminating waste in US health care.JAMA. 2012;307(14):1513-6. doi: 10.1001/jama.2012.362. [PubMed: 22419800].

15. Collins RA, Wisniewski MK, Waters JH, Triulzi DJ, Yazer MH. Effectiveness of multiple initiatives to reduce blood component wastage. Am J Clin Pathol. 2015;143(3):329-35. doi: 10.1309/AJCP42WMHSSTPHXI. [PubMed: 25696790].

16. Mundfrom DJ, Shaw DG, Ke TL. Minimum Sample Size Recommendations for Conducting Factor Analyses. Int J Test. 2005;5(2):159-68. doi: 10.1207/s15327574ijt0502_4.

17. Venugopal D, Rafi AM, Innah SJ, Puthayath BT. Evaluation of process excellence tools in improving donor flow management in a tertiary care hospital in South India. Asian J Transfus Sci. 2017;11(2):135-9. doi: 10.4103/0973-6247.214354. [PubMed: 28970681]. [PubMed Central: PMC5613420].

18. Jovanović R, Delić M, Kamberović B, Vulanović S, Radlovački V. Planning the use of lean six sigma as a framework for blood bank management improvements. Int J Indust Engin Manag. 2013;4(4):237-44.

19. Improta G, Balato G, Romano M, Carpentieri F, Bifulco P, Alessandro Russo M, et al. Lean Six Sigma: a new approach to the management of patients undergoing prosthetic hip replacement surgery. J Eval Clin Pract. 2015;21(4):662-72. doi: 10.1111/jep.12361. [PubMed: 25958776].

20. Toledo AH, Carroll T, Arnold E, Tulu Z, Caffey T, Kearns LE, et al. Reducing liver transplant length of stay: a Lean Six Sigma approach. Prog Transplant. 2013;23(4):350-64. doi: 10.7182/pit2013226. [PubMed: 24311399].

21. Soleymani M, Sepehri MM, Shams Asenjan K. Designing an RFID- enabled wasteless system for hemovigilance. Sci J Iran Blood Transfus Organ. 2016;13(3):185-96.

22. Alavi-Moghaddam M, Bardeh M, Alimohammadi $H$, Emami $H$, Hosseini-Zijoud SM. Blood Transfusion Practice before and after Implementation of Type and Screen Protocol in Emergency Department of a University Affiliated Hospital in Iran. Emerg Med Int. 2014;2014:316463. doi: 10.1155/2014/316463. [PubMed: 25254117]. [PubMed Central: PMC4165738].

23. Najafi M, Ahmadi A, Zolfagharinia H. Blood inventory management in hospitals: Considering supply and demand uncertainty and blood transshipment possibility. Operat Res Health Care. 2017;15:43-56. doi: 10.1016/j.orhc.2017.08.006.

24. Brue G. Six Sigma for managers. McGraw-Hill Education;2015. p. 30-58.

25. Whitney GM, Woods MC, France DJ, Austin TM, Deegan RJ, Paroskie A, et al. Reducing intraoperative red blood cell unit wastage in a large academic medical center. Transfusion. 2015;55(11):2752-8. doi: 10.1111/trf.13214. [PubMed: 26202213]. [PubMed Central: PMC4658658].

26. Kanani A, Vachhani J, Dholakiya S, Upadhyay S. Analysis on discard of blood and its products with suggested possible strategies to reduce its occurrence in a blood bank of tertiary care hospital in Western India.GlobJ Transfusion Med.2017;2(2).doi:10.4103/gjtm.gjtm_34_17.

27. Javadzadeh Shahshahani H, Taghvaee N, Akhavan Tafti F. Frequency of Blood Components Wastage and Associated Factors in Yazd Healthcare Centers. Iran J Blood Cancer. 2016;8(4):112-6.

28. Anani H, Baluchi I, Ghazizadeh M, Mardani Valandani H, Mirzaee Khalilabadi R. Evaluating the effect of tariff on wastage and return of blood products in Kerman province. Transfus Clin Biol. 2018;25(1):44-8. doi: 10.1016/j.tracli.2017.10.004. [PubMed: 29157876].

29. Mohammadbeigi A, Mohammadsalehi N, Aligol M. Validity and reliability of the instruments and types of measurments in health applied researches. J Rafsanjan Univ Med Sci. 2015;13(12):1153-70.

30. Lawshe CH. A Quantitative Approach to Content Validity. Person Psychol.1975;28(4):563-75. doi: 10.1111/j.1744-6570.1975.tb01393.x.

31. Javadzadeh Shahshahani H, Taghvai N. Blood wastage management in a regional blood transfusion centre. Transfus Med. 2017;27 Suppl 5:348-53. doi: 10.1111/tme.12433. [PubMed: 28661077].

32. Bots M, de Grouw EP, van Rooyen-Schreurs IH, van den Akker GJ, Sturk A, Klinkspoor JH, et al. Strategies to reduce wastage of red blood cell units. Vox Sang. 2016;110(2):143-9. doi: 10.1111/vox.12351. [PubMed: 26509641].

33. Hashemi SM, Soleimanzadeh Mousavi SH, Tavakolikia Z. Determining Model for Maximum Blood Request(MSBOS) for Surgery: An Elective Surgery in Imam Ali Hospital, Zahedan, Iran. Int J Hematol Oncol Stem Cell Res. 2019;13(2):95-101. [PubMed: 31372203]. [PubMed Central: PMC6660480].

34. Pena JR, Dzik WS. Utilization management in the blood transfusion service. Clin Chim Acta. 2014;427:178-82. doi: 10.1016/j.cca.2013.09.030. [PubMed: 24080431]. [PubMed Central: PMC4403789].

35. Stanger SH, Yates N, Wilding R, Cotton S. Blood inventory management: hospital best practice. Transfus Med Rev. 2012;26(2):153-63. doi: 10.1016/j.tmrv.2011.09.001. [PubMed: 22018647]. 